\title{
Construction and Performance Evaluation of Savonius Vertical Axis Wind Turbine
}

\author{
Y. Abdullahi, M. Musa
}

\begin{abstract}
Traditional horizontal-axis wind turbines are usually designed for areas with naturally high- swind speeds, but exhibit low performance when under low wind speed. Vertical-axis wind turbines (VAWTs) provide an alternative that can be used in low-wind conditions. In this work, a Savonius vertical axis wind turbine with two blades was designed, constructed and installed. Its actual field performance was tested at Sokoto Nigeria. The result showed that, the turbine produced power of $125.0 \mathrm{~W}$ at a wind speed of $10.38 \mathrm{~m} / \mathrm{s}$ with efficiency of $19.68 \%$. Therefore, it can be concluded that, by optimizing the selection of materials and fabrication method, the Savonius two-bladed vertical axis wind turbine can be very useful in powering some low energy consumption appliances especially at locations that are far away from the grid.
\end{abstract}

Index Terms - Fabrication, Savonius, Two-bladed, Turbine, Vertical axis.

\section{INTRODUCTION}

Energy plays a central role in economic development and industrialization of any nation. Fossil fuels have been the major resources that supply the world's energy demand. However, fossil fuel reserves are limited and usage of fossil fuels to generate energy has negative environmental effects. As a result, energy policies of many nations are organized towards ensuring a supply of reliable, economical and environmentally friendly energy resources in a form that supports the targets for growth and social developments through the use of resources that are renewable in nature. Wind energy applications have been described as an economic and environmentally friendly solution to the urgent energy problems of many countries (David, 2008).

\subsection{Wind Turbines}

Wind turbines are machines that generate electricity from the kinetic energy of the wind (Erich, 2013). It can harness a plentiful energy source from wind which can be converted into electricity for human activities and it doesn't release any harmful gases or pollutants to the environment in the process of generating electricity (Mukund, 2006). It can be classified according to axis of rotation (Dan et al., 2009) as shown in Figure 1:

Y. Abdullahi, Department of Science Laboratory Technology. Umaru Ali Shinkafi Polytechnic Sokoto

M. Musa,Mechanical Engineering Department, Usmanu Danfodiyo University Sokoto

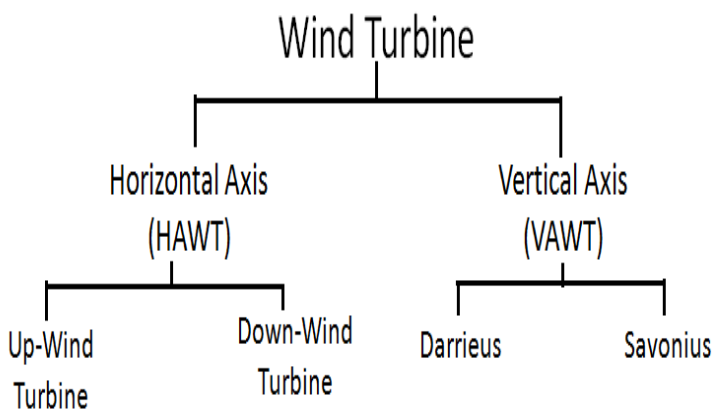

Figure 1: Classification of Wind Turbine

For horizontal axis wind turbine, the axis of the rotor's rotation is parallel to the wind stream and the ground. Most HAWTs today are two- or three-bladed, though some may have fewer or more blades (Wei, 2010). Their major advantages are: they have higher efficiency and better performance compared to VAWT. Their drawbacks are: their construction costs are very high, regular turbulence produced leads to structural failure and require an additional yaw control mechanism to turn the blades toward the wind (Mukund, 2006).

In the case of VAWT, the rotor rotates vertically around its axis instead of horizontally. It is easier and simple to build, and it can be mounted close to the ground (Wei, 2010). There are two types of vertical axis wind turbine: Darrieus and savonius.

The Darrieus vertical axis wind turbine is composed of a vertical rotor and several vertically oriented blades. A small powered motor is required to start its rotation, since it is not self-starting. When the wind passing through the airfoils generate torque and thus, the rotor is driven around by the wind, the Darrieus turbine is then powered by the lift forces produced by the airfoils. The blades allow the turbine to reach speeds that are higher than the actual speed of the wind, thus, this makes them well-suited to electricity generation when there is a turbulent wind., but it uses 2-3 straight blades individually attached to the vertical axis instead of curved blades. It is also applicable to use helical blades attached around the vertical axis to minimize the pulsating torque (Wei, 2010).

The Savonius wind turbine is one of the simplest turbines. It is a drag-type device that consists of two to three scoops. Because the scoop is curved, the drag when it is moving with the wind is more than when it is moving against the wind. This differential drag is now what causes the Savonius turbine to spin. Because they are drag-type devices, this kind of turbine extracts much less than the wind power extracted by the previous types of turbine (Wei, 2010, David et al., 2011). 
In this work, Savonius Vertical Axis Wind turbine was designed and constructed by considering 2 blade numbers and its actual field performance was evaluated.

1.2 Wind Power Theory:

Wind is an effect caused as a result of pressure differences over regions and heights in the atmosphere (Tiwari and Mishra, 2011). The force carried by the wind can be converted to electricity by connecting several components together forming a system called Wind Energy Conversion System (WECS) as shown in Figure 2:

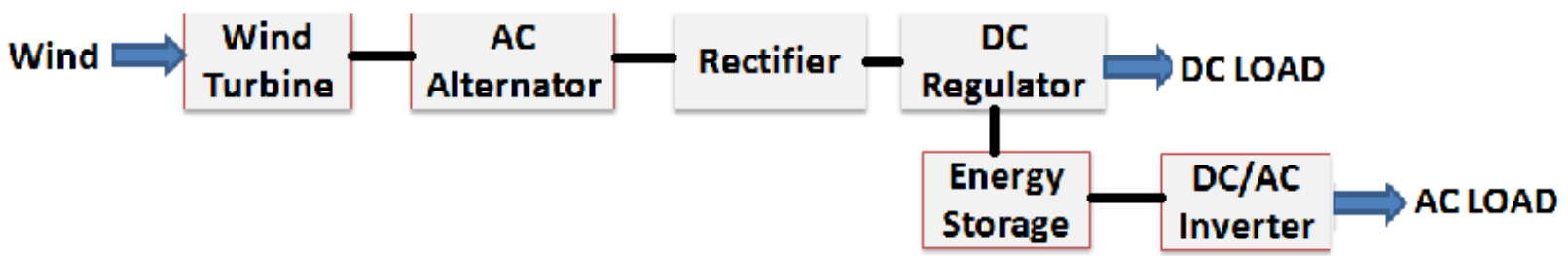

Figure 2: Block Diagram of Wind Energy Conversion System

At an instant of time, the power available for mass flow rate of air $\dot{m}$ passing through an area $A_{\text {with kinetic energy }}$ $\frac{1}{2} M V^{2}$ is 2012; Mostafaeipour et al., 2014):

$$
P_{w}=\frac{1}{2} \dot{m} U^{2}=\frac{1}{2}(\rho A U) U^{2}=\frac{1}{2} \rho A U^{3}
$$

Therefore, power available depends upon many parameters: rotor area, wind speed and air density (a function of temperature, pressure and humidity). Since power is proportional to the cubic of wind speed, knowledge of the wind speed frequency distribution is of paramount importance. Wind speed at a given location is continuously varying which makes it difficult to predict the overall energy capture from a site. Hence to make meaningful estimations for long term energy capture, statistical methods are used (Shepherd and Shepherd, 2007; Kothari et al., 2012).

Also the power produced by the wind turbine depends on the power coefficient, ${ }^{C}$ p of the machine which is a function of turbine parameters such as blade design, tip angle and relationship between the rotor speed and wind speed. Its maximum theoretical value known as the Betz limit is $16 / 27$ or $\approx 0.593$ (Shepherd and Shepherd, 2007).

The axial flux generator uses the changing magnetic flux to produce a voltage. The voltage produced by each coil can be calculated using Faraday's law of induction.( Richard, 2003)

$$
\overline{\mathrm{V}}=-N \frac{d \varphi}{d t}
$$

Where: ${ }^{\mathbb{V}}=$ voltage produce $($ volt), $N=$ number of coil turns,$\varphi=$ magnetic flux $(\mathrm{Wb})$

A term known as the magnetic flux is formulated from the dot product of the area and the magnetic field density in a uniform field.

$$
\text { FLUX }=\phi B=B A \cos \theta
$$

In most cases a uniform magnetic field cannot be produced so the flux is calculated by the integral of the magnetic field with respect to the area.

$$
\varphi B=\int B \cdot d A
$$

Where: $B=$ magnetic field density (T), $A=$ cross-sectional area of the closed loop $\left(\mathrm{m}^{2}\right)$

A close approximation of the induced voltage can be taken using the dot product. (Nathan, 2004).

\section{SYSTEM CONSTRUCTION DETAILS}

\subsection{Wind Turbine}

The main components of vertical axis wind turbine are: rotor and base. The rotor consists of blades made up of 18 gauge mild steel iron sheet while base is constructed using angle iron.

\subsubsection{Blade Dimension of the Rotor}

The height of the rotor was chosen to be $2.44 \mathrm{~m}$ with $0.19 \mathrm{~m}$ diameter; while the blades length and diameter were chosen to be $0.045 \mathrm{~m}$ and $2.75 \mathrm{~m}$ respectively. The rotor design is as shown in Figure 3.

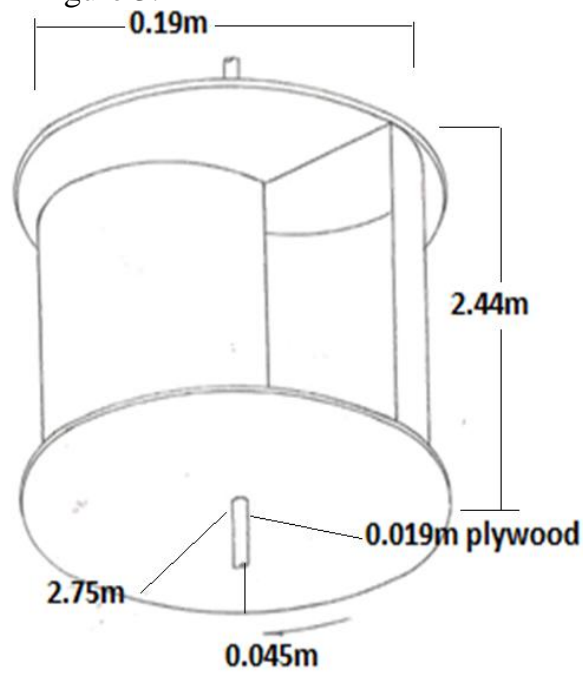

Figure 3: The Rotor Dimension

Based on the length of shaft and diameter of the rotor, the height and breadth of the triangular cage were chosen in order to allow the rotor rotate inside the cage. The Length, breadth and height were chosen to be $2.24 \mathrm{~m}, 1.95 \mathrm{~m}$ and $3.00 \mathrm{~m}$ respectively.

\subsubsection{Brake System}

The friction plate and brake system were designed as shown in Figure 4 and Figure 5 respectively.

\subsubsection{Description of Alternator}

The components of AC alternator are: stator and rotor. The stator consists of the electric field (the coil) while the rotor consists of the magnetic field. The stator and the rotor were designed as shown in Figure 6 and Figure 7 respectively. 

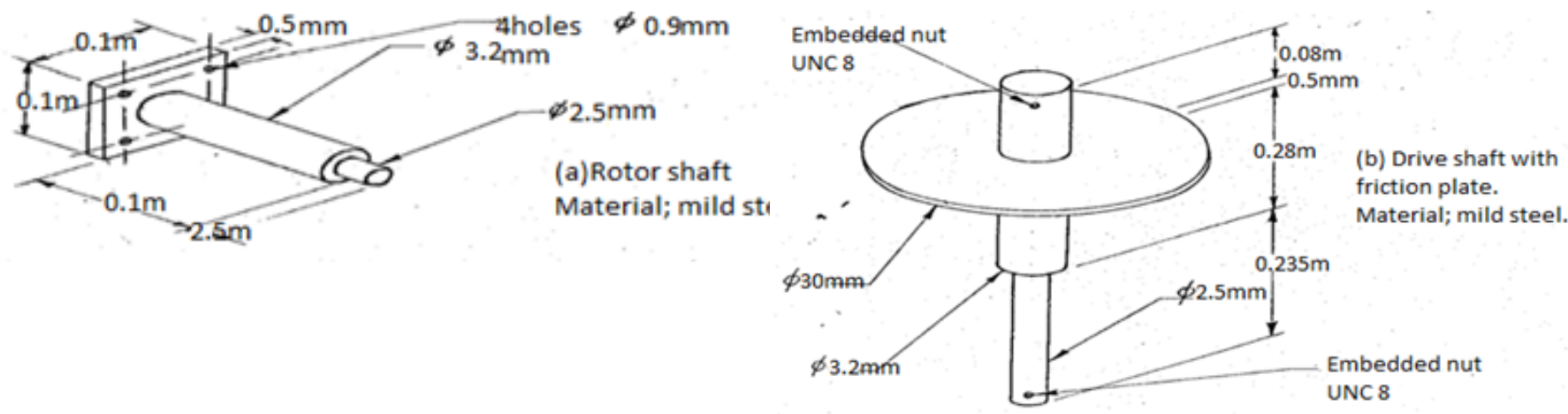

Figure 4: friction plate

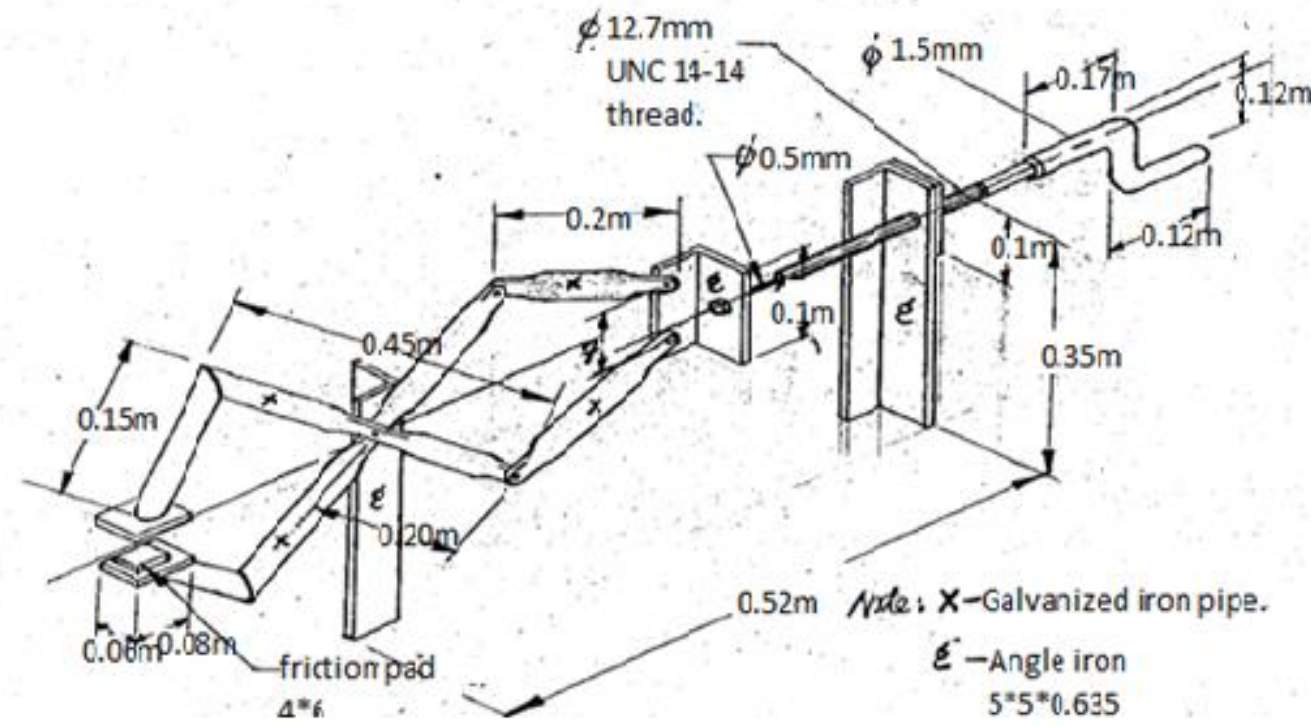

Figure 5: brake system

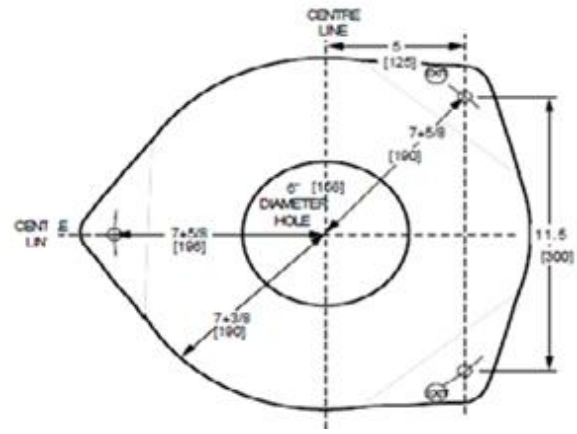

Figure 6: stator shape

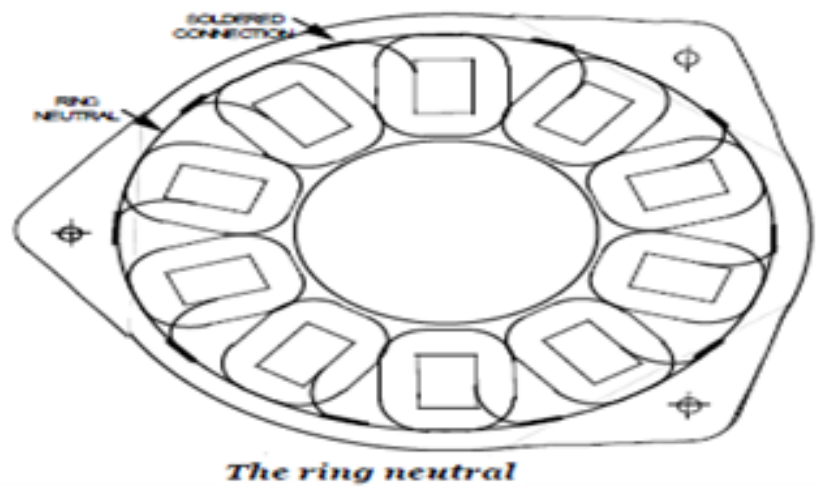

Figure 7: connected coils

When winding the coil, the magnet wire was chosen which suited the magnet size and battery voltage of $12 \mathrm{~V}$. Ten coils were designed and laid out in a circle which matched the magnet blocks. The spacing between the inner edges of the holes is $0.208 \mathrm{~m}$ for the metric magnets.

The wires were twisted together in a joint and the tip of the hot soldering iron was placed against the joint so as to achieve maximum contact area, then solder wire was feed into the point of contact between iron and joint the solder malt into the joint and assist with carrying heat further into the joint.

\subsection{Construction}

\subsubsection{Construction of Blade}

In the project two blades with vertical shaft with height and breadth of $2.44 \mathrm{~m}$ and $0.19 \mathrm{~m}$ respectively were constructed. The angle between the two blades is $180^{\circ}$ so if one blade moves other blade comes in the position of first blade. They are as shown in Figure 8.

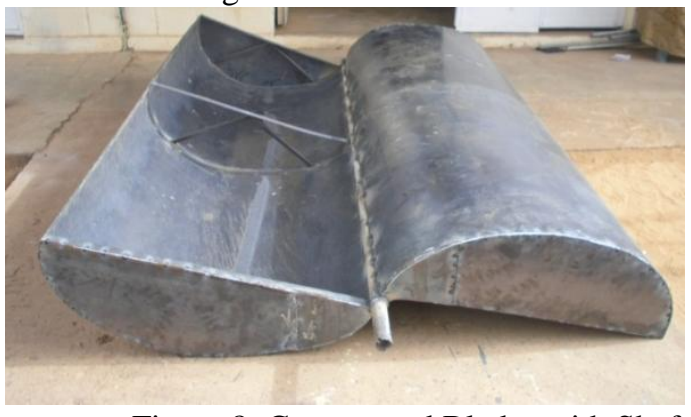

\subsubsection{Shaft Construction}

The shaft of the blades was constructed in such a way that it properly fitted to the blade. The shaft should be as possible as less in thickness \& light in weight for the two blades, the shaft used is very thin in size are all properly fitted. So no 
problem of slipping \& fraction is created, it is made up of iron pipe which is having very light weight. Length of shaft \& diameter of shaft are $2.75 \mathrm{~m} \& 0.045 \mathrm{~m}$ respectively, the bearings' shaft of length $0.26 \mathrm{~m}$ and diameter of $0.03 \mathrm{~m}$ was inserted at the top and bottom ends of constructed blades to give contact between base and shaft, as shown in Figure 9.

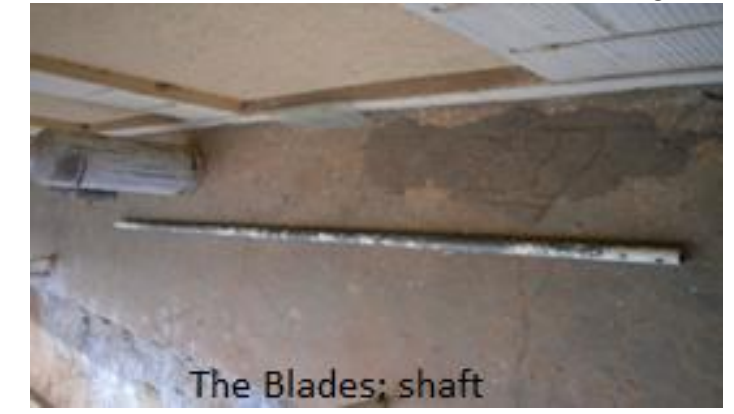

Figure 9: The Blades shaft Constructed

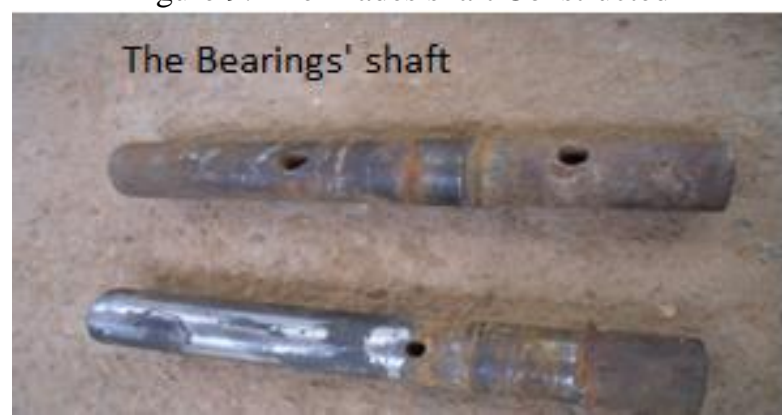

Figure 10: The Bearing shaft Constructed

\subsubsection{Construction of Bearings}

For the smooth operation of Shaft, bearing mechanism is used. To have very less friction loss, the two ends of blade's shaft are pivoted into the same dimension bearing of $0.07 \mathrm{~m}$. The Bearings has diameter of $0.07 \mathrm{~m}$ No.3032207 and $0.06 \mathrm{~m}$ No. 4T 32305c Bearing are generally provided for supporting the shaft and smooth operation of shaft. We have used tapered roller ball bearings for the purpose of ease of maintenance as shown in Figure 11.

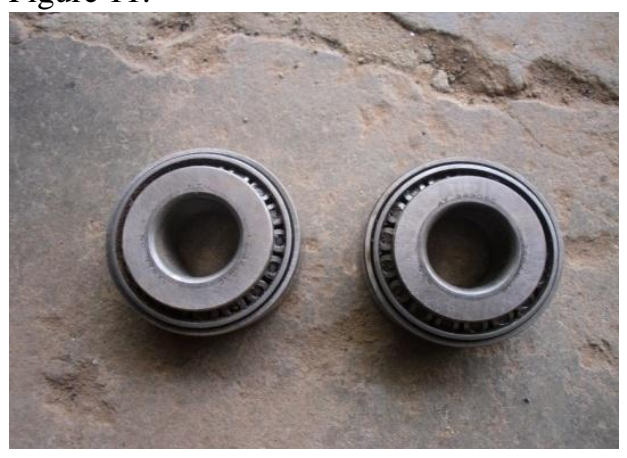

Figure 11: The Bearing

\subsubsection{Base Construction}

Some base is stronger than others. Base is important in the construction of the windmill because not only do they have to support the windmill, but they must also be subject to their own weight and the drag of the wind. If a weak

tower is subject to these elements, then it will surely collapse. In this project the triangular cage of length $2.795 \mathrm{~m}$ and breath $2.20 \mathrm{~m}$ was constructed from angle iron for blades' housing, the hole at center represents location of bearing as shown in Figure 12.

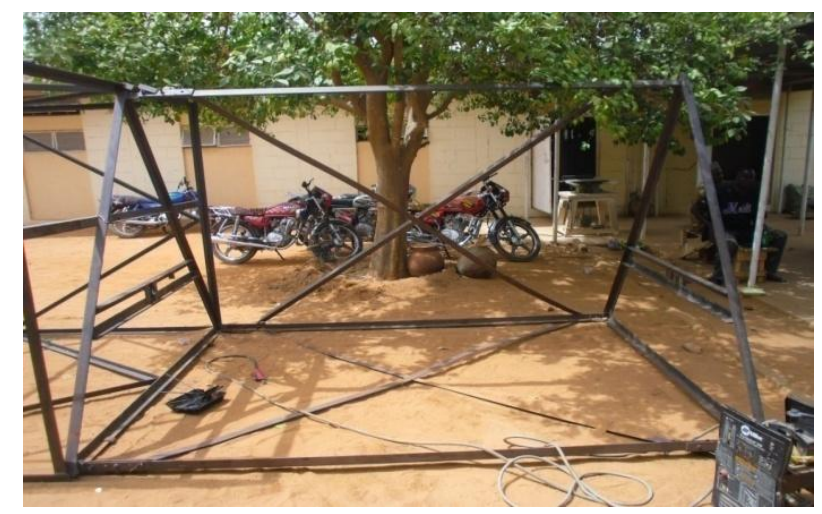

Figure 12: constructed triangular cage for blade housing

\subsubsection{Construction of Alternator}

The alternator mount was made from angle iron with three holes at triangle for positioning stator. Thick plywood was put and bolted on top of alternator mount for reducing the losses of current produced. The permanent magnet with nuts where placed on top of plywood and five bolts were bolted on each alternator mount's nuts to create the space between the stator and permanent magnet, then stator was placed on top of alternator mount's nuts and bolted as shown in Figure 13.

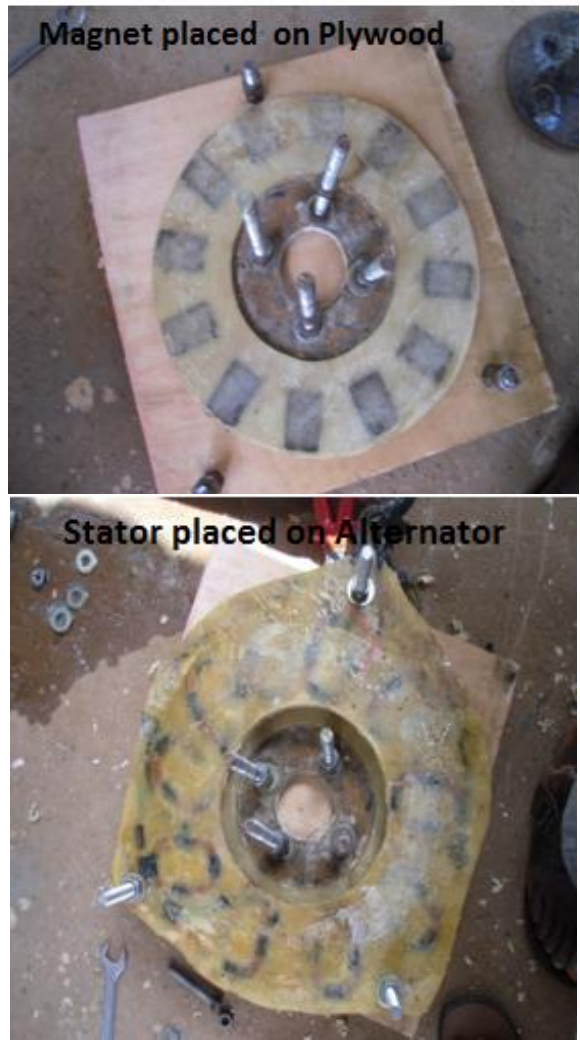

Figure 13: Design of Alternator

Full bridge rectifier was then connected with stator for conversion of the alternating current (ac) to direct current (dc) as shown in Figure 13. Finally the wind turbine system was coupled together as shown in Figure 14. 


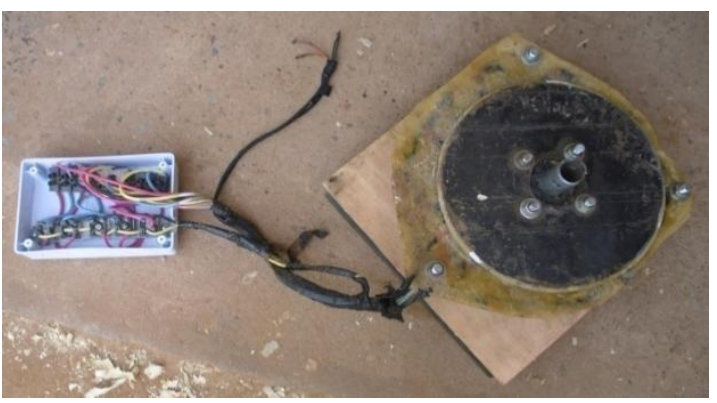

Figure 14: Rectifier connected with the stator

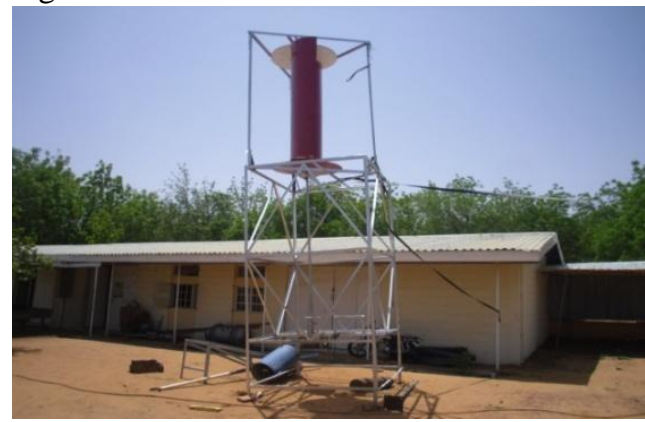

Figure 15: Complete Turbine System

\section{EXPERIMENTAL TESTING, RESULTS AND DisCUSSIONS}

After the alternator was fabricated and incorporated into the turbine assembly, the fully functioning system was ready for testing. The wind turbine testing was done on free space at Old Site of Sokoto Energy Research Centre, where wind speeds, angular velocity and voltage output from the vertical axis wind turbine (VAWT) were measured.

First the turbine was observed to be self starting and also responding to wind speed blowing from any direction. Based on this behavior of typical Savonious type vertical axis wind turbines, the data was observed from $4^{\text {th }}$ October to $1^{\text {st }}$ November, 2013.

The wind speeds, the voltage output between the positive and negative terminals from the DC generator, the angular velocity were measured using Digital Anemometer, Digital Multimeter, and Digital Tachometer respectively.

The theoretical power possessed by the wind following at a certain speed $u$ can be calculated from equation (1) given by:

$$
P_{w}=\frac{1}{2} \rho A u^{3}
$$

Where, $\rho=$ density of air $\left(1.225 \mathrm{~kg} / \mathrm{m}^{3}\right), \mathrm{A}=$ Swept area and $u=$ wind velocity $(\mathrm{m} / \mathrm{s})$

From Figure 8, the Length $\mathrm{L}$ and Breadth $\mathrm{B}$ of the blade are $2.44 \mathrm{~m}$ and $0.19 \mathrm{~m}$ respectively. Therefore, area of the blade A is given by:

$$
A=L * B=2.44 * 0.19=0.4636 \mathrm{~m}^{2}
$$

Since there are two blades, the total blades area = $0.9272 \mathrm{~m}^{2}$

Therefore, the power available to the blades are found by substituting air density and blades area in to equation 1 which results to:

$$
P_{A}=\frac{1}{2} \rho A u^{3}=\frac{1}{2} * 1.225 * 0.9272 * u^{3}
$$

Therefore, the available wind power depends on the velocity at that period given as:

$$
P_{A}=0.56791 * u^{3}
$$

The electrical power output obtained from the turbine is given by (Bent, 2011):

$$
P_{\theta}=I V=I^{2} R=V^{2} / R
$$

Where: $P_{e}$ is the electrical power obtained, $I$ is the current flowing, $V$ is the voltage between the terminals and $R$ is the resistance $(\Omega$, Ohms). A $5 \Omega$ resistor was chosen for this work.

The efficiency of the machine is defined as the ratio of electrical power obtained to the mechanical power available to the blades given by:

$$
\ell=\frac{P_{e}}{P_{A}} 100 \%
$$

Where, $P_{\theta}=$ electrical power output, $P_{A}=$ mechanical power available to the blades

The result obtained is summarized as shown in Table 1.

Table 1: Output Parameters of the Turbine

\begin{tabular}{cccccc}
\hline $\begin{array}{c}\text { Wind } \\
\text { Speed } \\
(\mathrm{m} / \mathrm{s})\end{array}$ & $\begin{array}{c}\text { Voltage } \\
(\mathrm{V})\end{array}$ & $\begin{array}{c}\text { Angular } \\
\text { Velocity } \\
(\mathrm{rpm})\end{array}$ & $\begin{array}{c}\text { Available } \\
\text { Power, } P_{A} \\
(\mathrm{~W})\end{array}$ & $\begin{array}{c}\text { Electrical } \\
\text { Power, } \\
P_{\Theta}(\mathrm{W})\end{array}$ & $\begin{array}{c}\text { Efficiency, } \\
(\%)\end{array}$ \\
\hline 0.46 & 0.11 & 130.3 & 0.06 & 0.002 & 4.38 \\
0.57 & 0.15 & 155.5 & 0.11 & 0.005 & 4.28 \\
0.92 & 0.28 & 163.4 & 0.44 & 0.02 & 3.55 \\
1.73 & 0.43 & 178.3 & 2.94 & 0.04 & 1.26 \\
2.31 & 1.00 & 204.3 & 7.00 & 0.20 & 2.86 \\
2.89 & 1.10 & 216.2 & 13.71 & 0.24 & 1.77 \\
3.5 & 2.50 & 295.3 & 24.35 & 1.25 & 5.13 \\
4.03 & 4.10 & 315.4 & 37.17 & 3.36 & 9.04 \\
4.6 & 5.30 & 330.3 & 55.28 & 5.62 & 10.16 \\
5.19 & 7.20 & 350.4 & 79.39 & 10.37 & 13.06 \\
5.77 & 8.60 & 405.3 & 109.10 & 14.79 & 13.56 \\
6.35 & 10.10 & 416.4 & 145.41 & 20.40 & 14.03 \\
6.92 & 11.40 & 435.5 & 188.19 & 25.99 & 13.81
\end{tabular}




\begin{tabular}{cccccc}
7.5 & 13.50 & 450.6 & 239.59 & 36.45 & 15.21 \\
8.07 & 16.00 & 466.4 & 298.47 & 51.20 & 17.15 \\
8.65 & 17.90 & 475.5 & 367.56 & 64.08 & 17.43 \\
9.2 & 19.60 & 489.4 & 442.22 & 76.83 & 17.37 \\
10.38 & 25.00 & 545.4 & 635.14 & 125.00 & 19.68 \\
\hline \multicolumn{5}{r}{ Zahedan, Iran. Elsevier: Renewable and Sustainable Energy Reviews, }
\end{tabular}

From the table it can be seen that the performance of the turbine was tested at a wind speed range of $0.46 \mathrm{~m} / \mathrm{s}$ $10.38 \mathrm{~m} / \mathrm{s}$. The voltage output ranges from $0.11 \mathrm{~V}$ at $0.46 \mathrm{~m} / \mathrm{s}$ to $25.0 \mathrm{~V}$ at $10.38 \mathrm{~m} / \mathrm{s}$ while the power output is near to zero up to speed of $3.5 \mathrm{~m} / \mathrm{s}$ and then increases to $125 \mathrm{~W}$ at $10.38 \mathrm{~m} / \mathrm{s}$. Therefore, it can be assumed that the cut in speed is about $3.5 \mathrm{~m} / \mathrm{s}$ while since the power output increases as wind speed increases in the whole range (does not stay constant with increase speed), it means that the rated speed is greater than $10.38 \mathrm{~m} / \mathrm{s}$. The efficiency ranges from $1.26 \%$ to $19.68 \%$.

\section{CONCLUSION AND RECOMMENDATION}

\subsection{Conclusion}

Savonius two-bladed vertical axis wind turbine was constructed. The turbine was tested in the field at Sokoto Nigeria; the data showed that the cut in wind speed of the turbine was about $3.5 \mathrm{~m} / \mathrm{s}$ and the turbine produced power of $125.0 \mathrm{~W}$ at a speed of $10.38 \mathrm{~m} / \mathrm{s}$ with efficiency of $19.68 \%$. Therefore, it can be concluded that, by optimizing the selection of materials and fabrication method, Savonius two-bladed vertical axis wind turbine can be very useful for low speedspower applications especially at locations that are far away from the grid.

\subsection{Recommendations}

The followings were recommended:

i. The testing is supposed to be repeated using wind tunnel to predict the performance of the turbine under different wind speeds.

ii. The turbine needs to be coupled with a simple reciprocating water pump for small scale water pumping and irrigation application to see its performance under such usages.

iii. The selection and fabrication method need to be optimized.

\section{REFERENCES}

[1] Bent, S. (2011). Renewable Energy: Physics Engineering, Environmental Impacts, Economics and Planning, $4^{\text {th }}$ Edition. The Boulevard, Langford Lane, Kodlongton, Oxford, UK Pg 232-245.

[2] Dan, C., Mick, S. \& Lan, W., (2009). Power From The Wind, Mother Earth News, New Society Publishers Canada. Pg 8

[3] David, A. \& Rivkia, L.S., (2013). The Art and Science of Wind Power, World Headquarters Jones \&Bartlett Leaning 5wall Street Burlington MA 01803

[4] David, P., (2008). Biofuels, Solar and Wind as Renewable Energy Systems: Benefits and Risks. Comell University, College Of Agriculture and Life Sciences 5126 Com stock Hall Ithaka, U.S.A Pg 5.

[5] Erich, H., (2013). Wind Turbines, Fundamentals, Technologies, Application, Economics, Third Translated Edition, Horst Von Renouard London, UK Pg 36

[6] Johnson, G. L. (2006) Wind Energy Systems. Prentice Hall International Inc., New Jerse, USA.

[7] Kothari, D. P.; Singal, K. C. \& Ranjan, R. (2012), Renewable Energy Sources and Emerging Technologies, second edition. PHI Learning Private Limited, New Delhi, India.

[8] Mostafaeipour, A.; Jadidi, M.; Mohammadi, K. \& Sedaghat, A. (2014). An analysis of wind energy potential and economic evaluation in
30(2014), 641-650.

[9] Mukund, R. P., (2006). Wind And Solar Power Sysem: Design , Analysis, And Operation Second Edition. C R C Press Taylor \& Francis Group (Publishers) US. Pg 15

[10] Nathan, I., (2004). Engineering Electromagnetic, Second Edition. Springer - Verlag New York, Pg 219.

[11] Richard, N., (2003). 101 Projects For Your Corvette 1984-1996. Galtier Plaza, Suite 200, 380 Jackson Street, St. Paul, MN 55101-3885 USA.

[12] Shepherd, W. \& Shepherd, D. W. (2007). Energy Studies (2 ${ }^{\text {nd }}$ ed.). Imperial College Press, Covent Garden, London.

[13] Tiwari, G. N. and Mishra, R.K., (2011). Advanced Renewable Energy Sources. Royal Society of Chemistry. Available Online at Www. Amazon .Com Accessed On $10^{\text {th }}$ October, 2013. Pg 457-458

[14] Wei, T., (2010) Wind Power Generation And Wind Turbine Design WIT Press USA Pg 30 